randomized investigation of stent grafts in aortic dissection trial. Circ Cardiovasc Interv. 2013;6:407-16.

4. Brunkwall J, Kasprzak P, Verhoeven E, Heijmen R, Taylor P, ADSORB Trialists, et al. Endovascular repair of acute uncomplicated aortic type B dissection promotes aortic remodelling: 1 year results of the ADSORB trial [published correction appears in Eur J Vasc Endovasc Surg. 2015;50:130. Böckler D [removed]; von Tenng-Kobligk H [corrected to von Tengg-Kobligk H]]. Eur J Vasc Endovasc Surg. 2014;48:285-91.
5. Kamman AV, Brunkwall J, Verhoeven EL, Heijmen RH, Trimarchi S, ADSORB trialists. Predictors of aortic growth in uncomplicated type B aortic dissection from the acute dissection stent grafting or best medical treatment (ADSORB) database. J Vasc Surg. 2017;65:964-71.e3.

6. Spinelli D, Benedetto F, Donato R, Piffaretti G, Marrocco-Trischitta MM Patel HJ, et al. Current evidence in predictors of aortic growth and events in acute type B aortic dissection. J Vasc Surg. 2018;68:1925-35.e8.
See Article page 1754

\section{Commentary: Modified frozen elephant trunk}

\author{
Reilly Hobbs, MD, MBS, and Ming-Sing Si, MD
}

Advances in the management of patients with acute type A aortic dissection have led to improved survival in this complicated cohort of patients. A study from the International Registry of Acute Aortic Dissections has shown that surgical mortality decreased from $25 \%$ to $18.4 \%$ over the last 2 decades, whereas mortality with medical management has remained relatively static. ${ }^{1}$ As survival has improved, more focus is being placed on strategies to decrease long-term morbidity and the need for reintervention after type A dissection repair. A significant number of patients will develop distal aortic pathology after type A dissection repair, especially if there is residual patent false lumen, connective tissue disease, intimal tears, and dilation beyond $4 \mathrm{~cm}$ in the descending aorta. $^{2}$ The frozen elephant trunk technique has been increasingly used to prevent distal aortic dilation and promote positive aortic remodeling over time. ${ }^{3}$ A frozen elephant trunk during type A dissection repair requires a total or partial arch replacement and deployment of an antegrade stent graft. A potential shortcoming of this technique is the necessity of a complex arch replacement in patients who may otherwise be better served with a more expedient hemiarch replacement.

Berdajs and colleagues ${ }^{4}$ have published their results using a modified frozen elephant trunk technique as their standard

\footnotetext{
From the Section of Pediatric Cardiovascular Surgery, Department of Cardiac Surgery, University of Michigan, Ann Arbor, Mich.

Disclosures: The authors reported no conflicts of interest.

The Journal policy requires editors and reviewers to disclose conflicts of interest and to decline handling or reviewing manuscripts for which they may have a conflict of interest. The editors and reviewers of this article have no conflicts of interest.

Received for publication May 21, 2020; revisions received May 21, 2020; accepted for publication May 21, 2020; available ahead of print June 17, 2020.

Address for reprints: Ming-Sing Si, MD, 11-735 C.S. Mott Children's Hospital SPC 4204, 1540 E Hospital Drive, Ann Arbor, MI 48109-4204 (E-mail: mingsing@ umich.edu).

J Thorac Cardiovasc Surg 2022;163:1763-4

$0022-5223 / \$ 36.00$

Copyright (c) 2020 by The American Association for Thoracic Surgery

https://doi.org/10.1016/j.jtcvs.2020.05.094
}

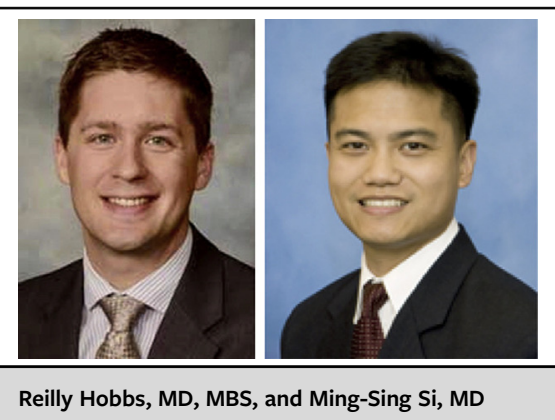

CENTRAL MESSAGE

A modification of the frozen elephant trunk may simplify the treatment of type A aortic dissection.

approach to acute type A dissection repair. In this modified technique, the authors perform a hemiarch replacement with deployment of an antegrade stent graft distal to the left subclavian artery. The stent is then anchored proximally with circumferentially placed interrupted pledgeted sutures. This technique is significantly less complex than a total or partial aortic arch replacement but retains the benefits of distal aortic stabilization, obliteration of the false lumen, and positive aortic remodeling. In their reported midterm results with an average follow-up of 3.9 years, Berdajs and colleagues ${ }^{4}$ observed an increased survival, a decreased risk for adverse events, and no difference in need for aortic interventions in patients treated with a modified frozen elephant trunk technique compared with their control group of isolated hemiarch replacement. Despite the promising midterm results, it is important to note that Berdajs and colleagues ${ }^{4}$ started using the modified frozen elephant trunk technique in 2009 and that it has been their standard approach since 2013. Patients treated with a modified frozen elephant trunk were thus disproportionately represented later in the study period than the control group. As we have repeatedly observed within the literature, many centers have had improved 
outcomes over this time period, independent of a modified technique. Additionally, distal aortic dilation occurs in a significant portion of patients after type A dissection repair; however, this is a chronic process, and an average followup of 3.9 years is not adequate to assess the success of the modified elephant trunk in preventing distal aortic complications. Another important question when considering this article is whether the control group is appropriate. Comparing differences between traditional elephant trunk and modified elephant trunk would have been more appropriate, but perhaps they did not have enough of these patients to use as a control.

Finally, in the current era, any discussion regarding aortic pathology and treatment would be remiss to neglect the mention of endovascular therapies. With the advent of branched stent grafts for aortic arch pathology and the relatively low morbidity of thoracic endovascular aortic repair (TEVAR), ${ }^{5,6}$ it is valid to ask if adding the complexity of a frozen elephant trunk, with total or hemiarch replacement, is reasonable given the relative ease and feasibility of future TEVAR. TEVAR also has the benefit of being able to perform endovascular ultrasound to ensure that the stent graft remains in the true lumen.
Berdajs and colleagues ${ }^{4}$ have presented an appealing technique for the management of acute type A dissection that may afford the benefits of antegrade stent grafting with the relative straightforwardness of a hemiarch replacement. This technique adds to the armamentarium of the aortic surgeon who must constantly balance the risk and complexity of the surgery at hand with the need for future interventions.

\section{References}

1. Evangelista A, Isselbacher EM, Bossone E, Gleason TG, Di Eusanio M, Sechtem U, et al. Insights from the international registry of acute aortic dissection: a 20-year experience of collaborative clinical research. Circulation. 2018;137:1846-60.

2. Leontyev S, Haag F, Davierwala PM, Lehmkuhl L, Borger MA, Etz CD, et al. Postoperative changes in the distal residual aorta after surgery for acute type A aortic dissection: impact of false lumen patency and size of descending aorta. $J$ Thorac Cardiovasc Surg. 2017;65:90-8.

3. Tian DH, Wan B, Di Eusanio M, Black D, Yan TD. A systematic review and metaanalysis on the safety and efficacy of the frozen elephant trunk technique in aortic arch surgery. Ann Cardiothorac Surg. 2013;2:581-91.

4. Berdajs DA, Koechlin L, Reid G, Grob F, Gahl B, Schurr U, et al. Modified frozen elephant trunk procedure as a standard approach in acute type A aortic dissection: a propensity-weighted analysis. J Thorac Cardiovasc Surg. 2022;163:1754-61.e3.

5. Bohan P. Comment on: indications for thoracic endovascular aortic repair (TEVAR): a brief review by Frank Manetta, MD, Joshua Newman, MS, Allan Mattia, MD. Int J Angiol. 2018;28:177-184. Int J Angiol. 2019;28:151-2.

6. Manetta F, Newman J, Mattia A. Indications for thoracic endovascular aortic repair (TEVAR): a brief review. Int J Angiol. 2018;27:177-84.

\section{Commentary: Proximal aortic dissection repair - when have things gone too far?}

\section{Sanjay Samy, MD, and Louis H. Stein, MD, PhD}

The Stanford classification denotes "type A" to be any dissection involving the proximal aorta regardless of the entry flap. The DeBakey classification system terms dissections involving the whole aorta type I. ${ }^{1}$ It then mirrors

From the Division of Cardiothoracic Surgery, Department of Surgery, Albany Medical College, Albany, NY

Disclosures: The authors reported no conflicts of interest.

The Journal policy requires editors and reviewers to disclose conflicts of interest and to decline handling or reviewing manuscripts for which they may have a conflict of interest. The editors and reviewers of this article have no conflicts of interest.

Received for publication June 1, 2020; revisions received June 1, 2020; accepted for publication June 2, 2020; available ahead of print June 26, 2020.

Address for reprints: Louis H. Stein, MD, PhD, Division of Cardiothoracic Surgery, Albany Medical Center, Surgeons Pavilion, 3rd Floor, 50 New Scotland Ave, Albany, NY 12208 (E-mail: steinl1@amc.edu).

J Thorac Cardiovasc Surg 2022;163:1764-5

0022-5223/\$36.00

Copyright (c) 2020 by The American Association for Thoracic Surgery

https://doi.org/10.1016/j.jtcvs.2020.06.045

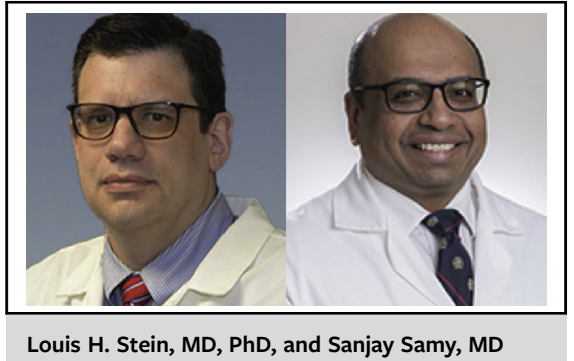

CENTRAL MESSAGE

Evidence supports modified

elephant trunk to treat patients

with type 1 DeBakey dissections.

Care must be taken evaluating

the anatomy of a patient's

dissection when selecting a

therapeutic approach. 